\title{
A multidisciplinary approach to improve drug therapy in nursing homes
}

This article was published in the following Dove Press journal:

Journal of Multidisciplinary Healthcare

10 January 2011

Number of times this article has been viewed

\author{
Malin Davidsson' \\ Olaug Elisabeth Vibe ${ }^{2}$ \\ Sabine Ruths ${ }^{3}$ \\ Hege Salvesen Blix ${ }^{4}$ \\ 'Lovisenberg Hospital Pharmacy, \\ Lovisenberg Diakonale Hospital, Oslo, \\ Norway; ${ }^{2}$ Cathinka Guldberg Centre, \\ Lovisenberg, Oslo, Norway; ${ }^{3}$ Research \\ Unit for General Practice, Uni Health, \\ Bergen, Norway; ${ }^{4}$ Department of \\ Pharmacoepidemiology, Norwegian \\ Institute of Public Health, Oslo, \\ Norway
}

\begin{abstract}
Management of drug therapy in nursing home patients is challenging due to complex health problems, use of multiple medications, and age-related changes in pharmacokinetics and pharmacodynamics. The objective of this study was, first, to examine the effect of systematic medication reviews conducted by multidisciplinary nursing home teams on prescribing quality and, second, to evaluate if drug therapy changes were maintained over time. Patients in a large nursing home in Oslo, Norway, were prospectively followed during a 1.5-year period. Systematic comprehensive medication reviews were carried out and the identified drug-related problems (DRPs) were discussed at multidisciplinary team meetings. After 3 months, the patients' drug regimens were reviewed again to evaluate if drug therapy changes were maintained. Altogether, 93 patients were included ( $89 \%$ women, mean age 87 years). In total, 234 DRPs were identified in 82 patients, and 151 drug therapy changes were performed in 73 patients. The most common DRPs were 'drug treatment without a clear indication' (37\% of all DRPs) and 'treatment with an inappropriate drug' (20\%). After 3 months, 85 patients (91\%) were available for follow-up. In these patients, $133(88 \%)$ of the drug therapy changes were maintained, and the mean number of DRPs had decreased from 2.6 to 1.0 per patient $(P<0.01)$. We were able to demonstrate that medication reviews conducted by multidisciplinary teams were effective to improve the quality of drug treatment in nursing home patients by significantly reducing both number of drugs and number of DRPs. The large majority of drug therapy changes were maintained after 3 months.
\end{abstract}

Keywords: drug-related problems, nursing homes, clinical pharmacists, multidisciplinary teams

\section{Introduction}

Nursing homes represent the largest institutional level in Norway, with about 40,000 beds, comprising about $14 \%$ of Norwegian citizens aged 80 years and over. ${ }^{1}$ Nursing home patients commonly suffer from complex health problems leading to polypharmacy. The complexity of drug therapy for these patients and age-related changes in pharmacokinetics and pharmacodynamics increase the risk of drug-related problems (DRPs) and make appropriate drug prescribing challenging. Norwegian nursing homes have registered nurses who administer drugs to patients. Although qualified nursing staff is available at all hours, medical care in nursing homes is most commonly provided by part-time engaged general practitioners. Research suggests a need for improved medication management in nursing homes. ${ }^{2,3}$ Inappropriate prescribing is associated with increased morbidity, hospitalization, and mortality ${ }^{4,5}$ and has important economical implications.
Correspondence: Hege Salvesen Blix Department of Pharmacoepidemiology, Norwegian Institute of Public Health, Marcus Thranes gt. 6, 0403 Oslo, Norway

Tel +4721078163

Fax $+4721078 \mid 46$

Email hege.salvesen.blix@fhi.no 
In the United States and Australia, quality of care for the elderly has been studied extensively, and managed care programs involving clinical pharmacists have been implemented in primary care. In Europe, such programs are scarce, except for the United Kingdom. Medication reviews in nursing homes by pharmacists are promising but not conclusive, and only few studies have had a multidisciplinary approach. ${ }^{6-10}$ Multidisciplinary team interventions including clinical pharmacists are effective to resolve DRPs in hospital settings, ${ }^{11}$ and a similar approach is expected to improve the quality of drug therapy in nursing homes.

The objective of this study was to examine the effect of systematic medication reviews conducted by multidisciplinary nursing home teams on prescribing quality and to evaluate if drug therapy changes were maintained over time.

\section{Methods}

\section{Study population}

A clinical pharmacist (author MD) prospectively recruited patients from one nursing home in Oslo, Norway, during a 1.5-year period from 2005 to 2007. In total, the nursing home comprised 127 beds on five different wards. Patients were enrolled ward by ward, but due to shortage of nursing staff, we were unable to include 34 patients from one of the wards.

Based on drug charts and medical records, the clinical pharmacist retrieved the following information for each patient: age, gender, all regular medications (brand name, formulation, strength, and dose), active medical conditions, and relevant laboratory tests (eg, glomerular filtration rate). The drugs were classified according to the Anatomical Therapeutic Chemical (ATC) classification system. ${ }^{12}$

The study was reported to the Regional Committee for Medical and Health Research Ethics, who presented no objection regarding the study design but concluded that committee clearance was not required. They regarded the project as quality improvement of medical care, implying that it was not necessary to obtain informed consent from the study participants. However, an information letter was sent to all patients and to patients' next of kin if the patients were diagnosed with dementia.

\section{DRPs}

The clinical pharmacist reviewed patients' drug list to identify DRPs, taking into account individual clinical characteristics. Norwegian drug therapy guidelines and a drug-drug interaction database were used as tools. ${ }^{13,14}$ A DRP was defined according to the Pharmaceutical Care Network Europe: 'an event or circumstance involving drug therapy that actually or potentially interferes with desired health outcomes'. ${ }^{15}$ The identified DRPs were classified according to a slightly modified Norwegian classification system. ${ }^{16}$ Nine DRP categories were applied: 1) treatment without clear indication, 2) inappropriate drug, 3) need for additional drug, 4) too high dose, 5) too low dose, 6) suboptimal dosing time or formulation, 7) adverse drug reactions (only those that are unavoidable and show symptoms are included), 8) lack of monitoring, and 9) drug-drug interaction. These DRPs are all potential causes of unfavorable clinical outcomes. Although classified as DRPs in many studies, in this study, preventable adverse events (ADEs) or therapeutic failure were regarded to be symptoms of the underlying causes; therefore, $\mathrm{ADE}$ is not included as a separate category in the DRP registration.

The identified DRPs were discussed with the physician and nurses in charge at regular multidisciplinary case conferences, and drug therapy changes were suggested. The nursing home physician held the final decision whether drug therapy changes should be performed or not. After 3 months, the patients' drug charts were reviewed again by the clinical pharmacist to evaluate if drug therapy changes were maintained. The change in number of DRPs was used as a measure of improvement in prescribing quality.

\section{Statistical analyses}

Changes in numbers of drugs used and numbers of DRPs before and 3 months after the multidisciplinary case conferences were analyzed by Wilcoxon signed rank test. $P$ values $<0.05$ were regarded as statistically significant. SPSS software (version 15.0 for Windows; SPSS Inc., Chicago, IL) was used for the analyses.

\section{Results}

Altogether, 93 nursing home patients were included. Women comprised $89 \%$ of the population and mean age was 87 years (SD, 8.3; range, 52-102). The patients used an average of 7.5 regular drugs. The most commonly used drugs were analgesics (ATC groups N02 and M01), which were used by $70 \%$ of the patients, laxatives (ATC group A06A) (67\%), antidepressants (ATC group N06A) (46\%), loop diuretics (ATC group C03C) (42\%), and antithrombotic drugs (ATC group B01) (46\%).

The pharmacist identified 234 DRPs in $82(88 \%)$ of the patients. The number of DRPs per patient ranged from 0 to 7 (average, 2.5 DRPs/patient). After discussion with the multidisciplinary teams, 151 drug therapy changes were performed in 73 patients. Table 1 shows that the most commonly acknowledged DRPs were 'drug treatment without a 
Table I Number (and \%) of DRPs discussed in the multidisciplinary team, changes made, changes maintained after 3 months, and drugs most frequently associated with DRPs in 93 nursing home patients

\begin{tabular}{|c|c|c|c|c|c|}
\hline \multirow{2}{*}{$\begin{array}{l}\text { Type of DRP } \\
\text { discussed }\end{array}$} & \multirow[t]{2}{*}{$\mathbf{N}(\%)$} & \multicolumn{3}{|c|}{ Management outcome } & \multirow{2}{*}{$\begin{array}{l}\text { Drugs most frequently } \\
\text { involved (number of times } \\
\text { with DRPs) }\end{array}$} \\
\hline & & $\begin{array}{l}\text { Changes not } \\
\text { made, } \mathbf{N}(\%)\end{array}$ & $\begin{array}{l}\text { Changes } \\
\text { made, N (\%) }\end{array}$ & $\begin{array}{l}\text { Changes maintained } \\
\text { after } 3 \text { months (\% of the } \\
\text { changes made), } \mathbf{N}(\%)\end{array}$ & \\
\hline $\begin{array}{l}\text { Treatment without } \\
\text { clear indication }\end{array}$ & $87(37)$ & 34 (39) & $53(6 I)$ & $43(8 I)$ & $\begin{array}{l}\text { Acetylsalicylic acid (7), } \\
\text { citalopram (7), furosemide (8), } \\
\text { haloperidol (4) }\end{array}$ \\
\hline $\begin{array}{l}\text { Inappropriate } \\
\text { drug choice }\end{array}$ & $46(20)$ & $22(48)$ & $24(52)$ & $20(83)$ & $\begin{array}{l}\text { Hydroxyzine ( } 7) \text {, zopiclone ( } 3) \text {, } \\
\text { senna glycosides (3), } \\
\text { alimemazine ( } 3 \text { ) }\end{array}$ \\
\hline Drug-drug interaction & $26(I I)$ & $16(62)$ & $10(38)$ & $8(80)$ & $\begin{array}{l}\text { Paracetamol/codeine } \\
\text { combination (9), metoprolol (5), } \\
\text { oxazepam (6), escitalopram (4) }\end{array}$ \\
\hline Too high dose & $24(10)$ & $4(17)$ & $20(83)$ & $20(100)$ & $\begin{array}{l}\text { Furosemide }(4) \text {, memantine }(2) \text {, } \\
\text { sodium picosulfate }(2)\end{array}$ \\
\hline Too low dose & $22(9)$ & $6(27)$ & $16(73)$ & $15(94)$ & $\begin{array}{l}\text { Paracetamol }(6), \text { calcium/ } \\
\text { vitamin D combination }(2)\end{array}$ \\
\hline Lack of monitoring & $18(8)$ & 0 & $18(100)$ & - & $\begin{array}{l}\text { Levothyroxine sodium (4), } \\
\text { enalapril (4) }\end{array}$ \\
\hline $\begin{array}{l}\text { Suboptimal dosing } \\
\text { time or formulation }\end{array}$ & $6(3)$ & 0 & $6(100)$ & $5(83)$ & - \\
\hline Need for additional drug & $5(2)$ & I (20) & $4(80)$ & $4(100)$ & - \\
\hline Adverse drug reactions & 0 & 0 & - & - & - \\
\hline Total & $234(100)$ & $83(35)$ & $15 \mid(65)$ & $133(88)$ & - \\
\hline
\end{tabular}

clear indication', 'inappropriate drug choice', and 'drug-drug interaction'.

Eighty-five (91\%) patients were eligible for follow-up after 3 months. Seven patients had died and one was hospitalized, and, therefore, nine drug therapy changes performed in these patients were not available for follow-up. Altogether, $133(88 \%)$ of the changes performed after multidisciplinary case conferences were maintained after 3 months.

Of the 234 DRPs discussed, 151 (65\%) were acted upon. For the remaining DRPs, changes were not performed (Table 1). 'Suboptimal dosing time or formulation', 'too high dose', and 'need for additional drug' were the DRPs that most frequently led to drug therapy changes (Table 2). On the other hand, 'drug-drug interaction' was least likely to bring about changes. Drug discontinuation (44\% of all drug therapy changes) and dose adjustment (32\%) were the most common changes.

Three months after intervention, the average number of drugs used per patient had decreased from $7.4(\mathrm{SD}=3.3)$ to $6.8(\mathrm{SD}=3.5), P<0.01$, while the number of DRPs per patient had decreased from $2.52(\mathrm{SD}=1.7)$ to $1.05(\mathrm{SD}=1.4)$, $P<0.01$.

Table 2 Type of changes made according to DRP category

\begin{tabular}{|c|c|c|c|c|c|c|c|c|c|}
\hline \multirow[t]{2}{*}{ Type of change } & \multicolumn{9}{|l|}{ DRP category } \\
\hline & $\begin{array}{l}\text { No clear } \\
\text { indication } \\
\text { for drug use }\end{array}$ & $\begin{array}{l}\text { Inappropriate } \\
\text { drug choice }\end{array}$ & $\begin{array}{l}\text { Drug-drug } \\
\text { interaction }\end{array}$ & $\begin{array}{l}\text { Too } \\
\text { high } \\
\text { dose }\end{array}$ & $\begin{array}{l}\text { Too } \\
\text { low } \\
\text { dose }\end{array}$ & $\begin{array}{l}\text { Lack of } \\
\text { monitoring }\end{array}$ & $\begin{array}{l}\text { Suboptimal } \\
\text { dosing time or } \\
\text { formulation }\end{array}$ & $\begin{array}{l}\text { Need for } \\
\text { additional } \\
\text { drug }\end{array}$ & Total \\
\hline $\begin{array}{l}\text { Drug } \\
\text { discontinuation }\end{array}$ & 40 & 15 & 1 & 1 & - & - & 1 & - & 58 \\
\hline Dose adjustment & 2 & 2 & 4 & 18 & 15 & - & 1 & - & 42 \\
\hline Monitoring & - & - & 3 & I & - & 18 & - & - & 22 \\
\hline $\begin{array}{l}\text { Drug switch/change } \\
\text { of administration }\end{array}$ & I & 3 & - & - & - & - & 3 & 1 & 8 \\
\hline Addition of a new drug & - & - & - & - & - & - & - & 3 & 3 \\
\hline Total & 43 & 20 & 8 & 20 & 15 & 18 & 5 & 4 & 133 \\
\hline
\end{tabular}

Notes: Data collected 3 months after intervention. 


\section{Discussion}

In the present study, DRPs were identified in nearly $90 \%$ of the patients. Following multidisciplinary case conferences, the average numbers of DRPs were significantly reduced by $60 \%$ from 2.6 to 1.3 . Moreover, almost $90 \%$ of the changes were maintained after 3 months. These results indicate that medication reviews conducted by multidisciplinary teams are effective to improve the quality of drug treatment in nursing home patients.

To our knowledge, only a few studies using a comparable multidisciplinary model in nursing homes have previously been conducted (ie, two Dutch studies, ${ }^{17,18}$ one Swedish study, ${ }^{19}$ one Australian study, ${ }^{8}$ and two Norwegian studies). ${ }^{9}, 10$ All these studies have shown a positive effect of this model on drug prescribing quality. Two studies used the Medication Appropriateness Index (MAI) to measure quality. ${ }^{8,18}$ Stuijt et al demonstrated an improvement in mean summed MAI from 23.7 before intervention to 16.0 after the intervention period $(P=0.013)$, while Crotty et al showed a change in the MAI with 4.1 in the intervention group compared to 0.4 in the control group $(P<0.001)$. In one of the other studies, a reduction of 1.7 problems per patient was shown, ${ }^{17}$ which is comparable to our study. In line with our findings, this latter study also demonstrated a reduction in the overall drug use. ${ }^{17}$ Reduced drug use is probably an indicator of medication quality in this aging population, and it also implies substantially reduced costs for the nursing homes over time.

In our study, systematic medication reviews by a clinical pharmacist followed by face-to-face multidisciplinary case conferences were used to identify and resolve DRPs in a nursing home. Verrue et al performed a systematic review on pharmacists' interventions for the optimization of drug use and found mixed evidence for the effectiveness in the nursing home setting. ${ }^{20}$ One reason could be that in most studies, the pharmacist interventions have been in written form, that is, do not imply a direct communication with prescribers. ${ }^{7,21-23}$ In the United States, legislation demands monthly medication reviews (written comments) in nursing homes, ${ }^{24,25}$ and although clinical pharmacy services in the United States nursing homes have proven to reduce morbidity and mortality, DRPs are often reported in nursing homes. ${ }^{26}$ This is the reason why a new model implementing direct communication between professions has been suggested in the United States: the Fleetwood model of pharmaceutical care. ${ }^{25}$ Our findings support that direct communication between pharmacists and physicians is useful to obtain attention for DRPs and also accept for drug therapy changes in nursing homes.
Our study revealed DRPs in a large majority of nursing home patients (88\%), which is in accordance with previous studies. ${ }^{2,5}$ Moreover, in line with previous studies, we found 'lack of indication' to be the most common DRP. ${ }^{17-19}$ The high prevalence of this type of problem could be due to administrative system errors, for example lack of transmission of information when a patient moves into the nursing home, incomplete medical records, or suboptimal systems for monitoring of drug therapy.

Two-thirds of the performed medication changes comprised drug discontinuation or dose adjustment. These are changes that also have the potential to provide negative clinical outcomes for the patients. However, the fact that almost $90 \%$ of the changes were maintained after 3 months suggests the opposite. Three months is probably sufficient time to discover adverse effects of the changes such as the medical condition worsens after discontinuation of a drug. Thus, it could be interpreted that the interventions actually improved the quality of drug prescribing in the nursing home. Some of the identified DRPs discussed by the multidisciplinary team were decided not to act upon, and drug interactions were the type of DRP that were least intervened on. One of the reasons may be difficulty in communicating the potential outcome of the DRP to the physician or difficulty in finding more appropriate drug substitutes.

The strength of our study is the prospective approach and that the multidisciplinary case conferences were included in the regular clinical setting. Furthermore, the clinical pharmacist added to the team had vast experience in clinical work. The limitations are, of course, that the study was conducted in only one nursing home with one pharmacist. However, the present study provides evidence to postulate that joining intellectual forces in multidisciplinary teams can reduce both the number of drugs and the number of DRPs in nursing homes and, furthermore, that the vast majority of drug regimen changes maintains over time. Despite the limited sample size, the results indicate that medication reviews conducted by multidisciplinary teams are effective in improving quality of drug treatment in nursing home patients.

\section{Acknowledgments}

We thank the colleagues in the multidisciplinary teams at the nursing home for their positive attitude during the study performance. We also thank Dag Terje Finnbakk, director of the nursing home, and Jan Egil Røe, director of Lovisenberg Hospital Pharmacy, for making it possible to carry out the study. 


\section{Disclosure}

The authors report no conflicts of interest in this work.

\section{References}

1. Statistics Norway. Available from: http://www.ssb.no/. Accessed Aug 302009.

2. Ruths S, Straand J, Nygaard HA. Multidisciplinary medication review in nursing home residents: what are the most significant drug-related problems? The Bergen District Nursing Home (BEDNURS) study. Qual Saf Health Care. 2003;12(3):176-180.

3. Barber ND, Alldred DP, Raynor DK, et al. Care homes' use of medicines study: prevalence, causes and potential harm of medication errors in care homes for older people. Qual Saf Health Care. 2009;18(5): 341-346.

4. Lau DT, Kasper JD, Potter DE, Lyles A, Bennett RG. Hospitalization and death associated with potentially inappropriate medication prescriptions among elderly nursing home residents. Arch Intern Med. 2005; 165(1):68-74.

5. Handler SM, Wright RM, Ruby CM, Hanlon JT. Epidemiology of medication-related adverse events in nursing homes. Am J Geriatr Pharmacother. 2006;4(3):264-272.

6. Marcum ZA, Handler SM, Wright R, Hanlon JT. Interventions to improve suboptimal prescribing in nursing homes: a narrative review. Am J Geriatr Pharmacother. 2010;8(3):183-200.

7. Zermansky AG, Alldred DP, Petty DR, et al. Clinical medication review by a pharmacist of elderly people living in care homes - randomised controlled trial. Age Ageing. 2006;35(6):586-591.

8. Crotty M, Halbert J, Rowett D, et al. An outreach geriatric medication advisory service in residential aged care: a randomised controlled trial of case conferencing. Age Ageing. 2004;33(6):612-617.

9. Halvorsen KH, Ruths S, Granas AG, Viktil KK. Multidisciplinary intervention to identify and resolve drug-related problems in Norwegian nursing homes. Scand J Prim Health Care. 2010;28(2):82-88.

10. Kersten H, Ruths S, Wyller TB. Pharmacotherapy in nursing homes. Tidsskr Nor Laegeforen. 2009;129(17):1732-1735.

11. Kaboli PJ, Hoth AB, McClimon BJ, Schnipper JL. Clinical pharmacists and inpatient medical care: a systematic review. Arch Intern Med. 2006; 166(9):955-964.

12. WHO Collaborating Centre for Drug Statistics Methodology. ATC Index with DDDs 2008. Oslo, Sweden: WHO Collaborating Centre; 2008.

13. Norsk Legemiddelhåndbok for helsepersonell. Oslo, Sweden; 2006. Available from: http://www.legemiddelhandboka.no/. Accessed Aug 30 2010.
14. Molden E, editor. Cytokrom P450 (CYP)-Metabolism, Drug Interaction Database. Available from: http://www.cyp450.no/. Accessed Aug 30 2010.

15. van Mil JW, Westerlund LO, Hersberger KE, Schaefer MA. Drugrelated problem classification systems. Ann Pharmacother. 2004; 38(5):859-867.

16. Ruths S, Viktil KK, Blix HS. Classification of drug-related problems. Tidsskr Nor Laegeforen. 2007;127(23):3073-3076.

17. Finkers F, Maring JG, Boersma F, Taxis K. A study of medication reviews to identify drug-related problems of polypharmacy patients in the Dutch nursing home setting. J Clin Pharm Ther. 2007;32(5): $469-476$.

18. Stuijt CC, Franssen EJ, Egberts AC, Hudson SA. Appropriateness of prescribing among elderly patients in a Dutch residential home: observational study of outcomes after a pharmacist-led medication review. Drugs Aging. 2008;25(11):947-954.

19. Schmidt IK, Claesson CB, Westerholm B, Nilsson LG. Physician and staff assessments of drug interventions and outcomes in Swedish nursing homes. Ann Pharmacother. 1998;32(1):27-32.

20. Verrue CL, Petrovic M, Mehuys E, Remon JP, Vander Stichele R. Pharmacists' interventions for optimization of medication use in nursing homes: a systematic review. Drugs Aging. 2009;26(1):37-49.

21. Furniss L, Burns A, Craig SK, Scobie S, Cooke J, Faragher B. Effects of a pharmacist's medication review in nursing homes. Randomised controlled trial. Br J Psychiatry. 2000;176:563-567.

22. Roberts MS, Stokes JA, King MA, et al. Outcomes of a randomized controlled trial of a clinical pharmacy intervention in 52 nursing homes. Br J Clin Pharmacol. 2001;51(3):257-265.

23. Christensen D, Trygstad T, Sullivan R, Garmise J, Wegner SE. A pharmacy management intervention for optimizing drug therapy for nursing home patients. Am J Geriatr Pharmacother. 2004;2(4): 248-256.

24. Furniss L, Craig SK, Burns A. Medication use in nursing homes for elderly people. Int J Geriatr Psychiatry. 1998;13(7):433-439.

25. Hughes CM, Lapane KL. Administrative initiatives for reducing inappropriate prescribing of psychotropic drugs in nursing homes: how successful have they been? Drugs Aging. 2005;22(4):339-351.

26. Hansen RA, Greene SB, Williams CE, et al. Types of medication errors in North Carolina nursing homes: a target for quality improvement. Am J Geriatr Pharmacother. 2006;4(1):52-61.
Journal of Multidisciplinary Healthcare

\section{Publish your work in this journal}

The Journal of Multidisciplinary Healthcare is an international, peerreviewed open-access journal that aims to represent and publish research in healthcare areas delivered by practitioners of different disciplines. This includes studies and reviews conducted by multidisciplinary teams as well as research which evaluates the results or conduct of such teams or

\section{Dovepress}

healthcare processes in general. The journal covers a wide range of areas and welcomes submission from practitioners at all levels, from all over the world. The manuscript management system is completely online and includes a very quick and fair peer-review system. Visit http://www.dovepress.com/testimonials.php to read real quotes from published authors. 